\title{
Choanal atresia as a feature of ectrodactyly-ectodermal dysplasia-clefting (EEC) syndrome
}

\author{
JOHN CHRISTODOULOU*, PETER N McDOUGALL $\dagger$, AND \\ LESLIE J SHEFFIELD* \\ Departments of Genetics* and Neonatologyt, Royal Children's Hospital, Flemington Road, Parkville, \\ Victoria 3052, Australia.
}

SUMmARY We report here a father and daughter with digital abnormalities, nasolacrimal duct obstruction, and variable alopecia. The father had a cleft lip and palate and the daughter had choanal atresia. We propose they both have the EEC syndrome and show the variable expressivity of this disorder. Choanal atresia has not been previously reported in this condition.

The acronym EEC was first proposed by Rudiger et $a l^{1}$ for a disorder characterised by ectrodactyly (split hand deformity), ectodermal dysplasia, and cleft lip/palate. This is an autosomal dominant disorder and is notable for both reduced penetrance and variable expressivity. ${ }^{2-4} \mathrm{We}$ report here another family showing the intrafamilial variability of this disorder and highlight a feature not previously described.

\section{Case report}

The proband was born by vaginal delivery at 35 weeks' gestation to parents who were nonconsanguineous and of Caucasian descent. The pregnancy was complicated by an antepartum haemorrhage three days previously. Her Apgar scores at birth were 4 and 9 at one and five minutes respectively. Her birth weight was $2180 \mathrm{~g}$, occipito-
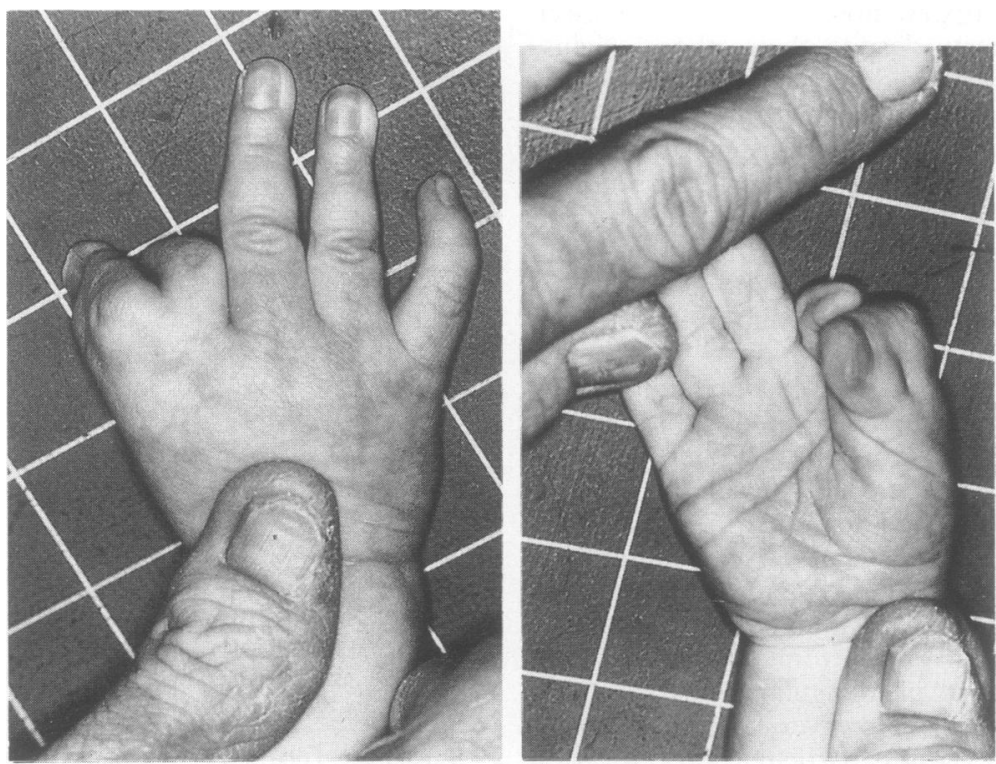

FIG 1 Right hand of the proband. Note the syndactyly of her thumb and index finger and a partially duplicated digit. Also note her father's spoon shaped finger nails. 
frontal circumference $31.0 \mathrm{~cm}$, and length $45 \mathrm{~cm}$, all of which were between the 10th and 50th centiles for gestational age.

She was noted to have a number of limb abnormalities. There was syndactyly of the thumb and index finger of the right hand. In addition there was

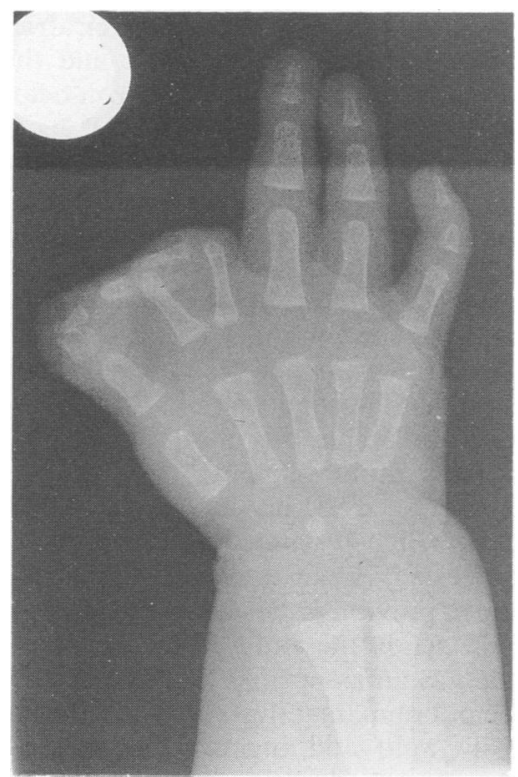

FIG $2 X$ ray of the proband's right hand. The extra digit has no distal phalanx. There is hypoplasia of the middle phalanx of the fifth finger.
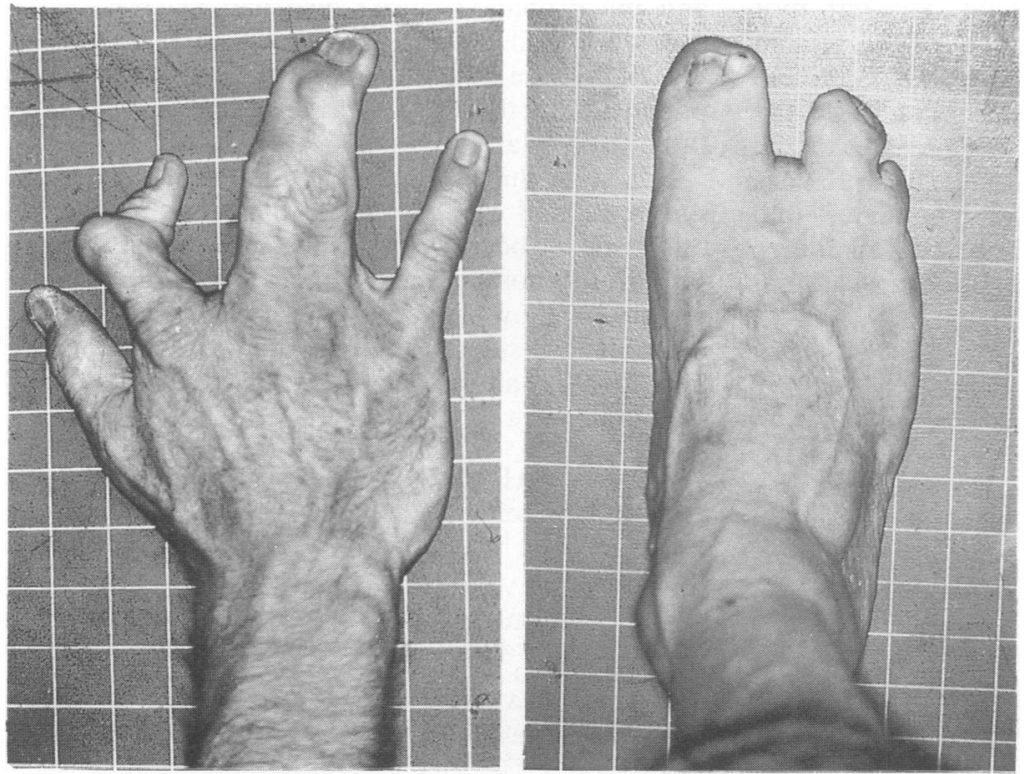

an extra incompletely formed digit on that hand (fig 1). She also had clinodactyly of the fifth finger. There was soft tissue syndactyly of the second and third toes of the right foot with dimples over both proximal tibiae. Her left hand and foot were normal.

She had no facial dysmorphism. Her scalp hair was rather sparse frontally and the eyebrows were barely visible. Ophthalmological assessment was normal. Her palate was normal and there were no lip pits. She was found to have bilateral choanal atresia, the obstruction being bony in origin. These were surgically opened and splinted with portex venting tubes.

She had had recurrent episodes of dacryocystitis in association with bilateral bony distal nasolacrimal duct obstruction. At five months of age the venting tubes were removed and she was subjected to lacrimal duct probing. On the right there was a mucocele with a very hypoplastic nasolacrimal punctum. On the left there was mild blockage involving the lower canaliculus. Because of continuing respiratory difficulties owing to upper airway obstruction it was necessary for the venting tubes to be reinserted two weeks later. A CT scan at that time showed that the posterior bony canals were narrowed bilaterally with the possibility of soft tissue obstruction.

A second attempt at removal of the venting tubes at eight months of age was unsuccessful, so she underwent a transpalatal repair of the choanal atresia at nine months of age. The venting tubes
FIG 3 Right hand and foot of the proband's father. (See text for description.) 
were removed at 11 months, at which time the rudimentary digit and index ray of the right hand were surgically amputated.

When reviewed at 11 months her weight and length were between the 50th and 75th centiles, while her head circumference was between the 75th and 90th centiles. There were no abnormalities of her nails and she was said to sweat normally. She had four teeth, all of which appeared normal, and there had been some improvement in her frontal hair cover. She could sit unaided and crawl. Speech development was normal for age.

Her karyotype was $46, \mathrm{XX}$ on $\mathrm{G}$ banding and cranial and renal ultrasounds were normal. An $x$ ray of her right hand (fig 2) clearly showed the polysyndactyly with absence of the distal phalanx of the extra digit.

Her father had surgical correction of a bilateral cleft lip and palate in childhood. He also had bilateral vesicoureteric reflux which required surgical reimplantation of the distal ureters. As a child he had recurrent eye infections which were attributed to blocked tear ducts. He sweated normally. His nails were somewhat spoon shaped and dysplastic. His teeth decayed rapidly after eruption and he was totally edentulous by early adulthood. He had male pattern balding, most obvious in his early twenties, but his body hair was otherwise normal. There was no other facial dysmorphism and he is of normal intellect. $\mathrm{He}$, too, had limb abnormalities. Syndactyly of his right thumb and index finger was surgically separated in childhood while syndactyly of the third and fourth fingers on that hand remain untreated (fig 3). His left hand was normal. His left foot showed partial soft tissue syndactyly of the second and third toes, while on the right there was complete syndactyly of the big toe with the second and the third with the fourth. The terminal phalanx of the fifth toe on that foot was hypoplastic (fig 3 ). There is no other family history of cleft lip/palate, limb abnormalities, or ectodermal tissue abnormalities. The proband's maternal grandfather and great aunt both have Huntington's disease.

\section{Discussion}

We believe this father and daughter have the EEC syndrome. There are a number of other disorders which are associated with ectodermal dysplasia and cleft lip/palate with or without digital abnormalities. The ectodermal dysplasia, ectrodactyly, muscular dystrophy (EEM) syndrome ${ }^{5}$ is an autosomal recessive condition and is associated with ocular abnormalities but no clefting of the lip/palate. The syndrome described by Ogur and Yuksel $^{6}$ differs $^{2}$ from the family described here in that their cases were the offspring of a consanguineous marriage, suggesting autosomal recessive inheritance, were dysmorphic and also intellectually handicapped. The family presented here is also clearly different from that reported by Bowen and Armstrong.? Apart from cleft lip/palate, digital anomalies, and features of ectodermal dysplasia, their patients were also notable for intellectual handicap, cicatricial skin defects, and eyelid adhesions. This and the HayWells syndrome (ankyloblepharon-ectodermal defects-cleft lip and palate syndrome $)^{8}$ have many overlapping features and may in fact be the same condition.

The EEC syndrome is a well defined disorder. Ectrodactyly may be of variable severity ranging from a lobster claw deformity to complete normality. ${ }^{3}$ The distal limb abnormalities in our cases fit within the range of abnormalities seen in this condition.

Cleft lip/palate is not seen in all subjects with the EEC syndrome, and this variation is seen both between and within families. ${ }^{9}$ The father of the proband had a cleft lip and palate, while the proband herself had a normal palate but bilateral choanal atresia. To our knowledge choanal atresia has not been previously described as being a feature of the EEC syndrome and we believe that it should be included as an associated feature.

The ectodermal manifestations of this disorder are usually mild and include any or all of the following: dental decay, abnormally shaped or absent teeth, variable alopecia, nail dystrophy, and lacrimal duct dysplasia. The patients described here both have mild alopecia and lacrimal duct dysplasia and the proband's father also had marked dental caries and nail dystrophy.

Renal abnormalities have also been described in patients with the EEC syndrome. ${ }^{10}$ The proband's father had bilateral vesicoureteric reflux.

It is clear that the proband's father has the EEC syndrome and we believe that the proband also has this disorder because her limb abnormalities are so similar to those of her father. Thus, this family serves to show the variable expressivity of this disorder. We suggest that choanal atresia should be included as an associated feature of the EEC syndrome.

$\mathrm{JC}$ is an NH and MRC Postgraduate Medical Research Scholar.

\footnotetext{
References

I Rudiger RA, Hoase W, Passarge E. Association of ectrodactyly, ectodermal dysplasia and cleft lip-palate. Am J Dis Child 1970;120:160-3.

2 Penchaszadeh VB, De Negrotti TC. Ectrodactyly-ectodermaldysplasia-clefting (EEC) syndrome: dominant inheritance and variable expression. J Med Genet 1976;13:281-4.
} 
${ }^{3}$ Kuster W, Majewski F, Meinecke P. EEC syndrome without ectrodactyly? Report of 8 cases. Clin Genet 1985;28:130-5.

${ }^{4}$ Majewski F, Kuster W. EEC syndrome sine sine. Clin Genet 1988;33:69-72.

5 Ohdo S, Hirayama K, Terawaki T. Association of ectodermal dysplasia, ectrodactyly, and macular dystrophy: the EEM syndrome. J Med Genet 1983;20:52-7.

6 Ogur G, Yuksel M. Association of syndactyly, ectodermal dysplasia, and cleft lip and palate: report of two sibs from Turkey. J Med Genet 1988;25:37-40.

${ }^{7}$ Bowen P, Armstrong HB. Ectodermal dysplasia, mental retardation, cleft lip/palate and other anomalies in three siblings. Clin Genet 1976;9:35-42.
${ }^{8}$ Greene SL, Michels VV, Doyle JA. Variable expression in ankyloblepharon-ectodermal defects-cleft lip and palate syndrome. Am J Med Genet 1987;27:207-12.

${ }^{9}$ Lewis MB, Pashayan HM. Ectrodactyly, cleft lip and palate in two half sibs. J Med Genet 1988;18:394-6.

${ }^{10}$ London R, Heredia RM, Israel J. Urinary tract involvement in the EEC syndrome. Am J Dis Child 1985;139:1191-3.

Correspondence to Dr J Christodoulou, Department of Genetics, Royal Children's Hospital, Flemington Road, Parkville, Victoria 3052, Australia. 